\title{
Definición, funciones y papel del espectador frente a la obra creativa ${ }^{*}$
}

\author{
José de Jesús Flores Figueroa** \\ Recibido: 2017-11-05. Enviado a pares: 2017-11 10. \\ Aprobado por pares: 2018-01-20. Aceptado: 2018-01-28 \\ https://doi.org/10.22395/angr.v17n33a6
}

\begin{abstract}
Resumen
En el presente artículo se exponen los resultados de la investigación acerca de la figura del espectador ante una obra creativa. Se hizo una revisión del estado del arte leyendo a varios autores que han tratado el tema del espectador, incluso de manera incidental. Este primer análisis nos llevó a pensar que no hay suficientes intentos para definir, ni al espectador ni su campo de acción cuando interactúa con un trabajo creativo. Como consecuencia, creemos que no hay bastante literatura científica actualizada sobre el concepto específico de espectador. Así nuestro objetivo es definir al espectador y sus relaciones con la obra creativa.

El método de la investigación fue la revisión documental, así como la reflexión crítica y, finalmente, la confrontación de conceptos. El primer resultado obtenido fue una definición de espectador: la persona que encuentra un rompimiento de la rutina a través del enfrentamiento con una obra creativa. Este encuentro puede ser accidental o provocado por el mismo espectador. De este contacto con la obra, es imprescindible que la persona interactúe con esta expresión. Asimismo, derivados de dicha propuesta, la persona puede obtener estímulos lúdicos, estéticos o culturales. Del mismo modo, planteamos 13 funciones que a nuestro criterio realiza todo espectador: 1. Buscar, 2. Crear expectativas, 3. Contemplar, 4. Juzgar, 5. Cuestionar 6. Creer 7. Descreer, 8. Discriminar, 9. Criticar, 10. Halagar, 11. Vituperar, 12. Aceptar, 13. Rechazar. Del mismo modo pensamos que el espectador solo se asume como tal, cuando ha rebasado cierto nivel de conocimiento sobre cierto tipo de obras, género o autores.

Palabras clave: definición de espectador, obra creativa, creador, funciones del espectador, conciencia del espectador.
\end{abstract}

El presente artículo de reflexión deriva de una investigación que el autor realizó en año sabático en la Universidad Estatal de Nuevo México, EE. UU. No tiene financiamiento de ninguna institución. Es parte de los trabajos del cuerpo académico Estudios y Enseñanza del Diseño de la Universidad Autónoma de Ciudad Juárez y va encaminado a comprender la manera en que los espectadores entienden y se apropian de la obra creativa. Este artículo forma parte del proyecto de la construcción del paradigma que se pretende construir alrededor del espectador. Fue escrito en el segundo semestre del 2017.

. Profesor investigador de la Universidad Autónoma de Ciudad Juárez, México, licenciado en Ciencias de la Comunicación, maestro en Artes Visuales y doctor en Letras Modernas. Áreas de investigación: narrativa y estética kitsch. jose.flores@uacj.mx Orcid: https://orcid.org/0000-0001-6266-5946 


\title{
Definition, duties and role of the viewer in the face of creative work
}

\begin{abstract}
In this paper, the results of the investigation about the figure of the spectator before a creative work are showed. A review of the state of the art was carried out by reading several authors who have addressed the issue of the viewer, even incidentally. This initial analysis led us to think that there are not enough attempts to define neither the viewer nor its field of action when interacting with a creative work. Consequently, we believe that there is not enough up-to-date scientific literature on the specific concept of the spectator. Thus, the goal of the research showed in this paper was to define the viewer and his links with the creative work. Documentary review, critical reflection, and confrontation of concepts were used as a research approach. The first result was a definition of the spectator: The person who finds a break in the routine through confrontation with a creative work. This encounter can be accidental, or it can be caused by the same spectator. From this contact with the work, it is essential that the person interacts with this expression. Likewise, stemming from the above, the person can obtain ludic, aesthetic or cultural stimuli. In the same way, we propose 13 functions that, in our opinion, all spectators perform: 1. Searching, 2. Creating expectations, 3. Contemplating, 4. Judging, 5. Questioning, 6. Believing, 7. Disbelieving, 8. Discriminating, 9. Criticizing, 10. Flattering, 11. Vilifying, 12. Accepting, 13. Rejecting. Likewise, we think that the spectator only assumes himself as such, when he has exceeded a certain level of knowledge about certain types of works, genres, or authors.
\end{abstract}

Keywords: definition of spectator, creative work, creator, spectator duties, spectator awareness.

\section{Definição, funções e papel do espectador em face da obra criativa}

\section{Resumo}

No presente artigo expõem-se os resultados da pesquisa a respeito da figura do espectador diante de uma obra criativa. Fez-se uma revisão do estado da arte lendo vários autores que trataram o tema do espectador, inclusive de maneira incidental. Essa primeira análise levou-nos a pensar que não há suficientes tentativas para definir, nem o espectador nem seu campo de ação quando interage com um trabalho criativo. Como consequência, achamos que não há bastante literatura científica atualizada sobre o conceito específico de espectador. Desse modo, nosso objetivo é definir o espectador e suas relações com a obra criativa. O método da pesquisa foi a revisão documental, bem como a reflexão crítica e, finalmente, a confrontação de conceitos. O primeiro resultado obtido foi uma definição de espectador: a pessoa que encontra uma ruptura da rotina por meio do confronto com uma obra criativa. Esse encontro pode ser acidental ou provocado pelo próprio espectador. Desse contato com a obra, é imprescindível que a pessoa interaja com essa expressão. Da mesma forma, derivados dessa proposta, a pessoa pode obter estímulos lúdicos, estéticos ou culturais. Desse modo, propomos 13 funções que a nosso critério realiza todo espectador: 1. Procurar, 2. Criar expectativas, 3. Contemplar, 4. Julgar, 5. Questionar 6. Acreditar 7. Desacreditar, 8. Discriminar, 9. Criticar, 10. Elogiar, 11. Vituperar, 12. Aceitar, 13. Rejeitar. Dessa forma, pensamos que o espectador só se assume como tal, quando ultrapassa certo nível de conhecimento sobre certo tipo de obras, gênero ou autores.

Palavras-chave: definição de espectador, obra criativa, criador, funções do espectador, consciência do espectador. 


\section{Introducción}

Abordar el tema del espectador puede parecer, de entrada, un trabajo poco redituable en términos conceptuales y que, por otro lado, aportaría poco a una comprensión de las relaciones entre el autor, la obra y quien se ofrece a contemplar esta última. Sin embargo, al revisar objetivamente el peso específico que tiene cada uno de estos elementos vemos que el autor casi siempre se define por la unicidad', al igual que la obra. En cambio, el espectador, a pesar de manejarse como singularidad gramatical, pueden contarse pluralmente, incluso por cientos de millones. Por otro lado, parece ser mucho más interesante hablar y abordar al autor ${ }^{2}$ por el misterio que implica el aparente regalo divino de la creatividad que recibe el productor de la propuesta. Asimismo, es atrayente hablar de la obra, del vehículo que soporta la muestra de la creatividad del autor y que cuando el creador deja de existir es el único testimonio del autor. Así, nuestro objetivo es definir al espectador y sus relaciones con la obra creativa.

Sin embargo, es claro que no puede existir una obra sin las personas que la contemplen, ni un autor sin obra publicada, pues no hay autor que cree para sí mismo y aunque así fuera, no sería coherente llamarlo creador pues no tendrá el contrapeso del espectador que equilibra la ecuación creativa. El autor no existiría sin ese espectador que cuestione la obra, que la critique, que la exalte o denueste, en una palabra: que influya de manera fundamental en la vida de la propuesta creativa, así como en el futuro del autor. De tal manera que, abordar al espectador como objeto de estudio, abre un panorama alentador no solo para ahondar en su naturaleza sino para completar y confrontar las posiciones que ya se hayan establecido alrededor de este fenómeno. A pesar de la relativa escasez de investigaciones, algunos teóricos ya han abordado el tema: "el término espectador (...) está en el centro de nuestras preocupaciones; no es, pues, al conjunto cuantitativamente configurado de los que contemplan que volvemos nuestra atención, sino a la subjetividad necesariamente involucrada en la relación de cada individuo con la obra" (De Souza, 2015, p. 332). Sin embargo, creo que el tema no ha sido, ni con mucho, agotado. Además, es posible que la propuesta de englobar en la misma categoría de espectador, a lectores de literatura, lectores de cómics, cinéfilos, contempladores de una obra de diseño, asistentes a una obra de teatro, a un concierto sinfónico o de rock, visitantes de un museo de $\operatorname{arte}^{3} \mathrm{O}$ interactivo, jugadores de videojuegos, televidentes, transeúntes que se topan

I Aunque si bien es cierto que muchas obras son colectivas, especialmente cuando son interpretativas, nunca igualarán al número de espectadores que las contemplan.

2 Es prudente decir que con el advenimiento de la web 2.0 las diferencias entre autor y espectador se modificaron sustancialmente y cada vez uno se parece más al otro. Baste dar dos ejemplos: los aficionados a cierto tipo de obras como ciencia ficción se atreven a producir y completar sus inclinaciones haciendo especulaciones o incluso derivaciones de las obras que les apasionan, tal es el caso del fandom o por otro lado del podcast que aborda O'Neill: "Una característica emergente de la transformación digital de la radio ha sido la diseminación de herramientas de producción en manos de miembros ordinarios del público, lo que los habilita para hacer y distribuir sus propios programas" (p. 3). Este mismo tema lo aborda O'Neill quien afirma que "El concepto de prosumption delinea, en términos generales contemporáneos, la noción que los usuarios de internet no solo son consumidores de los contenidos en línea, sino también productores" (2006, p. 5).

3 Es justo decirlo que no soy el primero en nombrar espectador a una persona que contempla una obra creativa, por ejemplo, Massara Sabeckis y Vallazza afirman que "es el propio cuerpo del espectador el que armará con su recorrido, 
con un espectáculo callejero e, inclusive, a personas que miran un anuncio de televisión provoque más de una opinión adversa, sin embargo hay más de una razón para hacer esta propuesta. Por lo pronto sigamos a Liebers y Schramm que señalan:

Un libro, una estación de radio, el actual éxito cinematográfico, el más reciente juego de computador, aunque estos entretenimientos pueden considerarse absolutamente diferentes, usualmente están generados alrededor de un carácter mediático que permiten al usuario sentirse íntimamente conectado a la historia y desarrollar un enlace emocional cuando comparte las aventuras del personaje. (2017, p 12).

Por otro lado, parece no existir una definición aceptada en términos generales del concepto de espectador y que vaya más allá de un diccionario. Del mismo modo no hay respuestas a preguntas nodales como ¿cuál es el papel de espectador? ¿ ¿cómo se definen y cuáles son las funciones que lleva a cabo el espectador durante su contemplación?, ¿hay diferentes tipos de espectador y, de ser así, cómo se pueden clasificar?, ¿̇la comprensión resultante de la interacción de una obra con quien la contempla es la misma para todos o se puede generar una escala, sobre qué bases y en todo caso cuáles serían?

Asimismo, aparecen cuestionamientos sobre los cuales no se ha arrojado suficiente luz para tener un panorama completo en la relación autor-obra-espectador. Por ejemplo: ¿cómo ocurre el proceso de comprensión de la obra por parte de un espectador ${ }^{5}$, ¿̇de qué habilidades echa mano el que contempla una propuesta creativa para comprenderla?, ¿el espectador puede entender más de lo que el autor puso conscientemente en su propuesta?

Luego de pasar la aduana del entendimiento, al espectador que rebasa el promedio le queda un estadio: el de la apropiación. Para este tipo de espectadores no basta solo con comprender, su pasión los impulsa a desarrollar mecanismos para que, en conjunto con otros espectadores de su clase, tomen posesión de la obra e incluso la intervengan ${ }^{6}$.

transitando los múltiples espacios [museos] en los que se nos ofrece la obra, los posibles relatos que surjan de las imágenes. La narración no es un a priori en muchas de las obras, sino que se conforma con el devenir temporal y espacial del propio espectador" (2018, p. 168), pero sí me parece que soy el primero que reúne bajo un solo nombre a quien lee un libro, juega un video juego, mira un anuncio publicitario, etcétera.

4 Como dicen Lopes y Loureiro, tradicionalmente el espectador es etiquetado como pasivo e incapaz de actuar, sin embargo, la tecnología confirma su poder y fortalece sus capacidades, así como sus habilidades para finalmente mostrar autonomía (2011, p. 205).

5 Así tenemos muchos intentos de resolver estas preguntas, por ejemplo "En el sentido más amplio, los estudios de la recepción buscan entender cómo las audiencias interactúan con los textos, enfatizando el análisis del tipo Bloom/ Christian en favor del análisis de audiencias. Frecuentemente, el énfasis se coloca sobre si las audiencias son pasivas consumidoras o activos generadores de significados. Mientas esto es debatido frecuentemente en referencia a la lectura en solitario, cuando se trata del estudio de mirar cine o televisión, la opinión popular es firme al afirmar que es pasivo" (Andersen, 2005, p. 3).

6 Aunque hay muchos tipos de apropiación de la obra, lo que importa es el final obtenido. Sin embargo, puedo ejemplificar con una específica: "Otro obvio ejemplo lo proveen las interpretaciones escénicas contemporáneas en las que el público es invitado a participar en la interpretación de una manera o de otra, voluntariamente o incluso contra su voluntad. En ambos casos el espectador siente, experimenta, que ha superado una doble barrera, la social entre audiencia y escenario con la que se traslada a una nueva posición en un espacio común compartido. La otra es 
En concreto, y después de analizar a las personas que se enfrentan a diferentes propuestas creativas (cualquiera que estas sean), llego a la afirmación de que todas comparten las mismas circunstancias y características, en consecuencia, es posible ubicarlas bajo un mismo parámetro: el del espectador.

\section{Metodología}

\section{La problemática del concepto de espectador}

Si miramos linealmente el proceso de contemplación de una obra, el espectador es el último de los elementos de la triada: autor, obra, espectador. En dicha ecuación, el peso específico de cada elemento es exactamente el mismo, dado que no puede existir un autor sin obra ni espectador ${ }^{7}$, ni una obra sin autor ni creador, como tampoco es posible pensar en un espectador sin autor ni obra.

Además, existen factores que, por cuestiones de percepción, hacen lucir más llamativos a los dos primeros. En el caso del autor, este destaca y se le concibe como una persona fuera de serie, como un elegido, como un genio, por su individualidad o incluso por su personalidad detonante en el proceso creativo, en consecuencia, a este personaje se le suele matizar más por su papel en el proceso de creación. Del mismo modo, la obra resalta por ser la herencia tangible del talento del creador. Como resultado, la propuesta creativa se presta a infinidad de interpretaciones que dependen de la conceptualización del evaluador que la contempla y aunque no es el tema de este artículo se puede decir que en toda obra aparecen por un lado los elementos narrativos y por el otro los elementos estéticos. Por otro lado, la naturaleza pasiva ${ }^{8}$ de la obra invita a su examen meticuloso prácticamente en cualquier circunstancia y desde cualquier punto de vista.

No obstante, el espectador, como último eslabón de este proceso, parece ser mucho más esquivo en términos definitorios y analíticos. En muchos sentidos aún no se han respondido totalmente las preguntas de qué es un espectador, cuáles son sus características, cuál es su papel y funciones en el proceso de la creación y entendimiento de una obra, así como cuáles son sus intenciones más allá de la necesidad estética. Sobre estas reflexiones se puede preguntar: ¿Es posible plantear una clasificación de espectadores en función de sus características? y de ser así, ¿̇cuáles son las características definitorias para esta categorización?, ¿todos los espectadores miran de la misma manera una obra?, ¿sabe el espectador que es un espectador? para luego, responder a la pregunta nodal de ¿qué nos convierte en espectadores?

física en la cual él acuerda asumir un rol, un cuerpo o la función que la actuación le sugiera. No importa lo desconcertantes que puedan ser estos momentos ni si son agradables, nos convierten en algo más reducido y simplificado comparado con nuestra posición anterior como espectadores autónomos e independientes" (Esa, pp. 82-83)

7 Es factible pensar que un autor puede crear para sí mismo, sin embargo, en este caso el autor juega una doble función que puede ser, y de hecho es, incluyente consigo mismo. Es decir, si la obra es contemplada únicamente por el propio autor este se convierte en espectador, incluso durante la construcción de la obra.

8 Pasiva en el sentido de permitir cualquier análisis en cualquier dirección, profundidad y velocidad. 
Como se sugiere líneas arriba, pareciera que la mayor parte de las reflexiones e investigaciones alrededor del proceso de creación y recreación de una obra se han inclinado más del lado del creador y de la obra. No obstante, también es cierto que a través del tiempo se han generado estudios alrededor del espectador y que se aborda desde diferentes perspectivas, pero en muchos casos, se cede a la tentación de descuidar al espectador, privilegiando los valores de la obra y la personalidad del autor, como resultado la intención de explicar al espectador queda trunca o se sesga de una manera u otra. Esto deriva en el cuestionamiento de si otras propuestas ${ }^{9}$ creativas no generan espectadores. Es decir ¿son espectadores los lectores de libros y revistas, los lectores de cómic, los escuchas de música, los asistentes al teatro, los jugadores de videojuegos, los que contemplan una escultura o una pintura, los receptores de una campaña de publicidad, etcétera? Finalmente, tal vez es tiempo de visualizar al espectador en campos más allá de los tradicionales; dado que, como se planteará más adelante, hay otros procesos en los que aparece el espectador como elemento fundamental del desarrollo de la creación y recreación de una obra.

\section{El espectador y las tentaciones en su abordaje como objeto de estudio}

Algunos autores han trabajado en la conformación del concepto del espectador, sin embargo, puedo reiterar que, desde mi punto de vista, no se ha llegado a una definición que explique la complejidad actual de este concepto. Parece que la falta de concretización de la noción de espectador se da fundamentalmente por tres razones:

- El investigador proponente del paradigma asume que, en términos conceptuales el lector comparte el mismo bagaje de él acerca del espectador, por lo que no define al espectador metódicamente.

- El investigador recula y termina analizando a la obra o al autor y pierde de vista al espectador.

- El investigador conceptualiza al espectador como elemento marginal y únicamente en los procesos del arte, del cine o de la televisión.

\section{El investigador proponente del paradigma asume que, en términos conceptuales el lector comparte el mismo bagaje que él acerca del espectador, por lo que no define al espectador metódicamente}

En alguna literatura que retoma al espectador o su relación con la obra, no se define al propio espectador, aunque es justo decir que tampoco se define a la obra ni al creador. Es factible suponer que esta dinámica se da en función de que la definición de la obra

\footnotetext{
La discusión se puede presentar dado que al menos tradicionalmente, se considera al creador como al que genera una obra reconocida por los cánones establecidos o está sancionada por expertos certificados ya sea de manera formal o informal. Para cuestiones prácticas, en esta propuesta sí es factible considerar obra a una propuesta generada por un espectador (que a través de este proceso se convierte a su vez en creador) y que se deriva de un trabajo creativo hecho por un autor legitimado como tal.
} 
(artística o no) evoluciona constantemente por lo que en la segunda década del siglo XXI resulta inconclusa. Por otro lado, y repasando nuestro objetivo, parece que si el estudioso pretende abordar de manera definitiva el paradigma del espectador es fundamental definir los elementos que componen a dicho fenómeno. En consecuencia, el propósito que nos ocupa es, precisamente, la definición y estudio del espectador como paradigma, cosa que, desde mi punto de vista, no se ha asumido en profundidad.

Para ilustrar esta afirmación revisemos un ejemplo: cuando Luz Aurora Pimentel desglosa las perspectivas de una obra desde el punto de la narrativa toca "la perspectiva del narrador" (2010, p. 97), "la perspectiva de los personajes" (2010, p. 115), "la perspectiva de la trama" (2010, p. 121) y "la perspectiva del lector" (2010, p.126) ${ }^{10}$. La autora comienza este último análisis sin dar una definición de lo que es el lector. Asume que quien consulta su obra puede definir o construir su concepción "de lector" con base en su propia experiencia y casarlo con los argumentos de la autora. Así, encontramos que Pimentel dice que "todo lector real está, por así decirlo, invitado a jugar un papel dentro del texto, a ocupar el lugar definido por el lector implícito, aunque es evidente que no estará obligado a ocuparlo de manera pasiva" (2010, p. 127).

Como vemos, no hay preámbulo y se entra de lleno a explicar las funciones y características del lector, es decir espectador para este artículo.

\section{El investigador recula y termina analizando a la obra o al autor y pierde de vista al espectador}

Muchos se inclinan, consciente o inconscientemente hacia la obra o, en el último de los casos, usan el concepto de espectador únicamente como título para abordar un tema completamente diferente. Así, Hernández y Martín apuntan que:

Uno de los fenómenos más significativos en el panorama artístico contemporáneo es la implicación cada vez mayor del público" en el proceso de creación artística. Este público ha pasado de ser mero receptor pasivo de una obra ya concluida —y cerrada - a intervenir activamente en ella, bien interpretándola, manipulándola o, incluso, formando parte físicamente de sus componentes. El disfrute de la obra se plantea como una interpretación y una ejecución, y en ese disfrute la obra revive en una perspectiva original. (1998, p. 45).

De entrada, los investigadores, hacen un razonamiento correcto en el sentido de que hoy el espectador se ha tornado activo ${ }^{12}$ (al menos en su relación con la obra artística) sin embargo después de una pequeña aproximación al espectador, nuevamente caen bajo la seducción de regresar al terreno de la obra y de:

10 Esta última perspectiva precisamente es la que me interesa examinar

1 El espectador, para nosotros.

12 En este punto es importante subrayar que, en mi concepción de espectador, este siempre ha sido activo. Pensemos simplemente en las obras teatrales a lo largo de la historia donde los espectadores interactuaban con los actores y su trabajo, pues los insultaban, halagaban, aplaudían, abucheaban o incluso les eran arrojadas cosas a manera de reprobación. 
El disfrute de la obra... interpretación y una ejecución [de la obra]... en ese disfrute la obra revive en una perspectiva original... La obra de arte... un mensaje fundamentalmente ambiguo, una pluralidad de significados que conviven en un solo significante. En buena parte del arte contemporáneo esta ambigüedad se va a constituir en una de sus finalidades explícitas. La noción de obra abierta que plantea Umberto Eco, referida a la pluralidad de significados de la obra de arte, no se propone como una categoría crítica, sino como un modelo útil para indicar, mediante una fórmula manejable, una dirección del arte contemporáneo ... y una nueva mecánica de la percepción estética. (1998, pp. 45-46).

En una relectura más detenida vemos cómo el principio de análisis del espectador se convierte en una retórica alrededor de la obra de arte.

\section{El investigador conceptualiza al espectador como elemento marginal en el proceso del arte, del cine o de la televisión}

Es factible que la cantidad de ensayos escritos alrededor del arte (por su longevidad al acompañar al hombre), del cine y de la televisión (por su presencia como medios de comunicación masiva con mayor penetración en el mundo antes de la expansión geométrica del internet) hagan inclinar la balanza en cuanto a los escritos a su alrededor. Sin embargo, este tipo de reflexiones adolecen del mismo defecto en cuanto a la mínima atención que se presta al concepto de espectador. Tomemos un ejemplo de esto y revisemos el análisis que hace Manuel Cerezo en su ensayo La televisión: del espectador ingenuo al espectador crítico:

La televisión parece tener una gran capacidad para producir un efecto de verdad, de verosimilitud, de autoridad sobre sus contenidos. Esta tendencia, llevada a sus últimas consecuencias, podría llegar a suplantar la conexión con la realidad de algunos espectadores particularmente adictos al medio, de tal manera que lo que aparece en televisión tendiera a ser más real y legitimador que la realidad misma. (1996, p. 16).

Al igual que los anteriores ejemplos, en su estudio el autor se enfoca en factores concretos del medio televisivo sin definir con antelación al espectador. Del mismo modo, su orientación se da directamente sobre la televisión al igual que muchos otros autores que tocan otros medios a través de los cuales llegan las obras al espectador.

Finalmente, hay una vertiente que parece tomar el concepto de espectador solo para titular un texto. A pesar de la riqueza de la obra de José Ortega y Gasset, este autor aborda el tema en una serie de ensayos (después compendiados en una antología denominada El espectador). Sin embargo, a pesar del título, su aproximación al espectador se da, más bien, sobre la descripción y crítica de obras específicas. Por ejemplo, usa cuatro o cinco páginas para tocar los puntos con lo que frisa el espectador sin abordarlo de lleno. Una vez que este autor toca el tema del espectador, prácticamente se separa de inmediato, concentrándose nuevamente en la obra. Asimismo, el filósofo remata con un pequeño Resumen de dos páginas una obra de Baroja, para después apuntar: "Y, sin embargo, Baroja no consigue introducirnos en la realidad por él inventada. Leemos éste como sus demás 
libros y al doblar la última página se nos borra de la fantasía cuanto nos ha contado" (Ortega y Gasset, 1985, p. 21). Es decir, este acercamiento de Ortega y Gasset se da más por el lado de la crítica al autor y a la obra que en la búsqueda de la cristalización de una definición del concepto de espectador. De hecho, sigue la dinámica de observacióndescripción-crítica de una obra.

\section{La ambigüedad resultante por la falta de definición del concepto de espectador y una propuesta de definición de espectador}

¿Con qué dificultades nos encontramos cuando no existe un sólido referente de la concepción de espectador?, ¿́por qué es importante definir al espectador con la mayor precisión posible, especialmente cuando lo vemos desde una nueva perspectiva e intentamos relacionarlo con obras no acordes a lo tradicional o lo ortodoxo? En función de esta cuestión es factible preguntar: ¿es el jugador de video juegos un espectador?, ¿la publicidad representa una obra, en consecuencia, hay un autor y un espectador?, ¿la persona que rechaza una obra es un espectador?, ¿el simple acto de abordar una obra sin cuestionarla o desecharla de inmediato convierte o no a esa persona en espectador?

Todas estas preguntas van relacionadas, precisamente, con las dificultades que se presentan cuando no tenemos una definición del concepto de espectador, en consecuencia, trataré de responderlas con las reflexiones que haré a lo largo del texto.

Para empezar, podemos revisar una definición que parece adecuada para generar una nueva concepción acorde al paradigma propuesto. Este concepto se deriva de la suma de la fisiología, sicología y arte y la propone Amount en su obra La imagen:

Las imágenes están hechas para ser vistas (...) el espectador (...) no puede definirse de modo sencillo y, en su relación con la imagen, deben utilizarse muchas determinaciones diferentes, contradictorias a veces; aparte de la capacidad y perceptiva, se movilizan en ellas el saber; los efectos y las creencias, ampliamente modeladas su vez por la pertenencia a región de la historia (a una clase social, a una época, a una cultura). (1992, p. 81).

Como dije, las perspectivas desde las cuales Amount define al espectador son la fisiología, la sicología y el arte. En la primera parte de la cita, encontramos la dificultad inicial de su propuesta pues no todas las imágenes son visuales, pues tenemos, por ejemplo, el caso de las imágenes mentales.

"Esto es básicamente porque la visión implica ver, para tener una dimensión sociocultural, se requiere de múltiples 'maneras de ver' y que son construidas sobre y por la cultura" (Lauwrens, 2012, p. 26). Lo que sí me parece correcto, especialmente para el punto que exploro, es el hecho de que deben tomarse en cuenta muchas variables para llegar a una conclusión coherente en cuanto al panorama que pretendemos abordar y que ambos autores señalaron correctamente, desde mi punto de vista. Sin embargo, a pesar de este acierto el autor falla, pues tampoco definen al espectador ni lo contemplan como objeto de estudio. 


\section{Reflexión crítica}

Ante lo que se puede considerar como la falta de una sólida concepción de espectador, iniciaré la construcción de una definición propia. Para empezar, se debe decir que el concepto de espectador variará sensiblemente del que aparece en los diccionarios. Así, por ejemplo, la Real Academia Española dice que espectador es el: "1. adj. Que mira con atención un objeto. 2. adj. Que asiste a un espectáculo público". Partir de esta definición plantea dos dificultades. La primera es que no todos los espectadores miran con la misma atención ${ }^{13}$ a la obra. Por ejemplo, la repetición de viejos programas de televisión. Es difícil encontrar un espectador que mire con menos interés una obra, que un televidente que ya ha visto el mismo programa varias veces, especialmente si es uno de baja calidad. La segunda dificultad implica cuestionar la asistencia del espectador a un evento. Desde la perspectiva en que abordo al espectador y que puede ser un lector de cómic, un lector de literatura, un televidente, un cinéfilo que mira una película en casa, etcétera, no es posible pensar que para ser espectador se tenga que asistir a un espectáculo público para ser precisamente un espectador.

Por otro lado, el término espectador, y dada su etimología latina: spectator, espectatoris, (que tiene el hábito de mirar y observar), comparte la raíz con el verbo spectare (contemplar o aguardar) de allí la relación semántica en español con el adjetivo expectante (que espera por algo venidero).

Para este texto obviaré la parte de la visualidad dado que, como dije, un espectador también puede participar, por ejemplo, en un concierto sinfónico. Sin embargo, sí comparto la noción de que todo espectador se relaciona con un espectáculo, pero no necesariamente público. Asimismo, es discutible y desechable la noción de esperar, pues si bien es cierto que muchas veces un espectador busca una relación directa con una obra creativa, también es cierto que en ocasiones la obra aparece ante su él de manera inesperada.

Por otro lado, si nos apegamos a este perfil de definición, quedarán muchos elementos dispersos y que parecen necesarios para construir un paradigma completo que defina al espectador.

Así, en este artículo y para cuestiones metodológicas, al espectador lo entenderemos no únicamente como la persona que espera u observa, sino como la que interactúa con una obra o que asiste a un espectáculo ya sea público o privado y que contempla un producto creativo pues como afirma Lauwrens "hay que recordar que el proceso de mirar es activo y complicado, en este, a un espectador se le urge a participar (desde una distancia 'segura') en la formación y coherencia de lo que se está viendo" (2012, p. 28). Del mismo modo, el espectador se entrega a la ilusión ofrecida por la obra con el fin de absorber los elementos que le presenta la propuesta creativa tal y como aseveran Heddon, Iball y Zerihan (2012):

13 Babatunde y Robs lo ejemplifican en su texto cuando afirman que el contexto cambia las perspectivas del espectador. "En el estadio los aficionados locales prefieren un triunfo rotundo por encima de una victoria cerrada. En cambio, los espectadores en casa prefieren un duelo cerrado por sobre un encuentro en donde un equipo gane por una amplia ventaja" (2007, p. 4) 
Crear un espacio dentro del proyecto creativo para lograr que el espectador se convierta en participante y el valor percibido de este tipo de actuación actúa sobre la visión de autenticidad ya que genera un cambio sobre la concepción de una relación entre el actuante y el espectador actuante. (p. 123)

Como resultado, defino al espectador como:

La persona que encuentra un rompimiento de la rutina a través del enfrentamiento con una obra creativa. Este encuentro puede ser accidental o provocado por el mismo espectador. De este contacto con la obra, es ineludible que la persona interactúe con esta expresión. Asimismo, derivados de dicha propuesta, la persona puede obtener estímulos lúdicos, estéticos o culturales.

Pese a todo, dar una definición sin clarificarla, para evitar malas interpretaciones, puede ser tan inútil como no tener una definición. Así, cuando digo que la persona encuentra, me refiero a que usualmente, durante la vida del individuo suelen crearse las condiciones para que entre en contacto con la obra. En términos generales, el individuo tiende a favorecer estas circunstancias, pero no siempre es así, de tal manera que, en algunas ocasiones, el sujeto se ve sorprendido por la obra y se convierte en espectador, inicialmente por circunstancias temporales, así como espaciales y luego por voluntad propia. En el primer caso, donde el espectador crea las circunstancias, esa persona puede planear y hacer una visita al cine, a una galería de arte, a un museo, leer un cómic, un libro, etcétera. En el segundo caso, ante esa misma persona puede aparecer un espectáculo callejero y ya sea que lo acepte o lo rechace, igualmente puede convertirse en espectador, aunque sea momentáneamente. En esta situación, él no buscó la obra, pero en ambos casos la persona enfrenta a la obra.

La vida cotidiana de las personas implica reiteración de tareas monótonas o habituales, es decir, rutina. Así, un rompimiento de esta, involucra suspender la inercia de los eventos reiterativos de la vida diaria de la persona, cosa que por otro lado es el objetivo de toda obra creativa. Cuando se afirma que este encuentro rompe la rutina se dice en el sentido en que la persona sale de una dinámica lineal de comportamiento y se sumerge (voluntaria o involuntariamente) en un comportamiento más bien lúdico ${ }^{14}$.

Mención más profunda requiere el concepto de obra, especialmente para el propósito y relación con la propuesta de espectador de este texto. Usualmente obra se utiliza en dos contextos por demás conocidos: obra de arte y obra comercial. En ambos casos parece que la obra está bien definida. En el caso del arte está la pintura, la escultura, el grabado, el happening, los performances, la música clásica y de cámara, el teatro de búsqueda, el cine de arte, etcétera, sin embargo, tiene el inconveniente que alrededor de esta "se crea un fetichismo en torno al objeto que es alimentado por todas las acciones que lo rodean, las colecciones, el valor del objeto y su cotización, o la posesión de obras de firma" (Moreno, 2006, p. 223). Por lo que toca a lo comercial, está el cine hollywoodense, la programación televisiva cotidiana, el teatro de revista, el circo, los espectáculos callejeros, el cómic,

14 No obstante, a veces el rompimiento de la rutina termina por instalarse en otra rutina. Caso concreto cuando un espectador enciende la televisión y a pesar de lo agradable o desagradable que le pueda parecer la programación se torna en una costumbre más, pero no deja de mirarla. 
la publicidad local o regional, la música comercial y popular, los videojuegos, y demás expresiones similares. Sin embargo, existe una zona gris, que según sea el investigador, coloca a las obras indistintamente dentro de lo comercial o de lo artístico. En este nivel de indefinición caben las propuestas creativas modernas y posmodernas como el Circo del Sol, las expresiones culturales tradicionales como el folclor y las artesanías, la publicidad nacional ${ }^{15}$, la literatura comercial y de esparcimiento, los cómics, los videojuegos, las páginas de internet, etcétera.

Para cuestiones prácticas, y acorde a la definición de espectador que propongo, no haré diferencia entre las obras de la zona artística, de la zona comercial y de la zona gris. Es decir, a la obra creativa la puntualizo como el objeto de atención de las personas. Es todo trabajo, de cualquier disciplina, encaminado al divertimento de la persona sin importar la catalogación de los expertos del arte o de lo comercial, pues el punto de vista que planteo pretende la generalidad. Esta posición va en concordancia con lo que afirma Chabot en cuanto a la obra:

Más que asumir que el texto habla de cierta manera a una audiencia específica, con un gusto alto o bajo, yo propongo que muchos espectadores son atraídos precisamente por esta conjunción "exótica" de estética opositora y puntos de vista diferentes, como lo sentimental y lo posmoderno, lo emocional y lo crítico, es decir el texto habla con uno y con otro, dialógicamente. $(2008$, p. 2)

Es decir, toda obra dice algo a todo espectador, siempre y cuando este último interactúe con la primera. Del mismo modo los estímulos lúdicos, estéticos o culturales son lo que aquí llamamos las intenciones del espectador y que abordaremos con mucha más profundidad en párrafos posteriores.

\section{Funciones del espectador}

Finalmente reitero: si no se da una interacción, el espectador no se logra. Como conclusión, cuando se plantea que el sujeto debe interactuar con la obra, me refiero a que debe ejercer las funciones propias de su papel de espectador: 1. Buscar, 2. Crear expectativas, 3. Contemplar, 4. Juzgar, 5. Cuestionar 6. Creer 7. Descreer, 8. Discriminar, 9. Criticar, 10. Halagar, 11. Vituperar, 12. Aceptar, 13. Rechazar ${ }^{16}$.

\section{Buscar}

Para las personas que pretenden convertirse en espectadores motu proprio, el paso inicial es la búsqueda. Esta función se da en tres niveles y se ejerce cuando la persona quiere provocar un cambio en su rutina.

\footnotetext{
15 Si bien es cierto que algunas propuestas creativas se repiten en otros niveles antes mencionados, tienen la diferencia en cuanto a los recursos en ellas invertidos, que en la mayoría de los casos se reflejan en el producto final.

16 Todos estos mecanismos sirven para interactuar con la obra. Es decir, la relación con la obra no solo implica una reacción positiva, sino que también puede ser negativa e incluso repelente.
} 
La primera opción de búsqueda se da cuando la persona sabe y desea contemplar una obra con características específicas, no solo en términos de género sino también en la forma en que se transmite. Por ejemplo, el espectador pretende encontrar la presentación universitaria de El rey Lear. Es decir, la intención es mucho más precisa en la mente del espectador. En consecuencia, dirige todos sus esfuerzos a ese terreno.

La segunda alternativa del espectador es la búsqueda de una propuesta creativa, pero solo en términos de género sin importar la manera en que se transmite. Es decir, en la mente del espectador la intención es menos más precisa. Contemplar la obra de El rey Lear en cualquier sustrato.

Finalmente, se presenta la pesquisa de una persona por una obra cualquiera. En ese momento al futuro espectador le da lo mismo encontrar una obra de teatro, un concierto, la proyección de un filme, el lanzamiento de una obra literaria, una conferencia o un cómic sin un tema específico. La persona se puede sumergir en un periódico, en un buscador de internet, en su propia colección de obras, en una calle comercial y, con base en sus hallazgos, decide cuál obra le atrae más y con ella se convertirá en espectador. Aquí la intención es absolutamente aleatoria e imprecisa y se basa únicamente en un deseo momentáneo de alejarse de la rutina cotidiana.

En los tres casos, el resultado es el mismo, por iniciativa propia la persona pretende convertirse en espectador a través del encuentro con una obra. Finalmente, es necesario apuntar que se exime de esta función al espectador que nace del encuentro fortuito con la obra, aquella que le sale al paso, pues la persona no tiene la intención de buscar y encontrar una propuesta creativa.

\section{Crear expectativas}

Una vez que la persona ha encontrado el tipo de obra a la que se quiere acercar, surge el espacio de tiempo donde el futuro espectador hace conjeturas acerca de lo que contemplará. Cuando existe esta búsqueda se da lo que Contreras y Gasca señalan como:

La afinidad afectiva de un individuo con una fotografía, una pintura, una caricatura, un filme o cualquier producto de la imaginación, son eventos emocionales para el observador. Por tanto, los marcadores somáticos también influyen en la aceptación del público para determinadas piezas artísticas. (2016, p 177).

Los marcadores somáticos son los estímulos gratificantes para un tipo de espectador. En consecuencia, en este periodo, el espectador puede generar perspectivas acerca de la calidad de la obra (con base en experiencias pasadas, comentarios de terceros, su búsqueda personal, de la fama o prestigio del autor), por lo que el espectador puede imaginar las perspectivas de la narrativa en el caso de que sea la continuación de una historia ya iniciada, etcétera. Asimismo, puede imaginar a futuro si la obra que contemplará será mejor o peor que otras versiones de la misma obra. Esta función es una de las que ofrece más alternativas para realizarse. Por ejemplo: las semanas previas a un evento deportivo, 
la espera del nuevo capítulo de una popular saga fílmica, la nueva novela de un escritor afamado, el inicio de una nueva temporada de una orquesta sinfónica, etcétera. En algunos casos, ciertos autores señalan que este proceso de expectativa tiende a desaparecer rápidamente, especialmente en el cine. Por ejemplo, Loscertales y Núñez (2008) señalan:

Ir al cine, independientemente de la película que se proyectase, era un momento de contacto comunitario de intercambios sociales, de pretexto para entablar, mantener y cosolidar [sic] todo tipo de relaciones..., toda una sociología urbana, cultural, grupal. Porque se debatía sobre la película a elegir y después se discutía ampliamente sobre lo que se había visto en la pantalla. (p. 140)

No obstante, creo factible decir que en el último tercio de la segunda década del siglo XXI, la costumbre de discutir todos los detalles acerca de qué filme mirar sigue vigente, especialmente con películas taquilleras. Por otro lado, esta función se ve alimentada con los mecanismos que los autores (o intermediarios que promueven las obras) o, incluso, otros aficionados a este tipo de obras, lanzan a través de los medios masivos, selectivos y personales de comunicación. Avances cinematográficos, publicidad, blogs, convenciones, redes sociales, etcétera.

\section{Contemplar}

Ya mencioné que el punto nodal en el que una persona se convierte en espectador es precisamente la contemplación activa de la obra, por muy efímera que esta sea.

Con esta función vale la pena hacer la diferenciación entre el espectador que busca una obra y el espectador que se encuentra de improviso con una oferta del creador. En el primer caso la contemplación se da desde que la persona establece el contacto inicial con la obra reconociéndola como tal. Es decir, puede ser un anuncio de revista, de radio, de televisión, un comentario de un tercero que hable del libro, del filme, de la obra de teatro, del concierto sinfónico, de la obra operística, del nuevo cómic, etcétera. El seguimiento que se da a esa primera vecindad es parte de la contemplación.

En cuanto a la persona que se convierte en espectador, porque la obra le sale al paso, el concepto de contemplación es más complejo pues en este sentido contemplar implica por definición reconocer que, ante lo que se está, es una obra. No basta con mirarla, escucharla o sentirla, indefectiblemente se le debe reconocer como tal. De no darse esta identificación, por parte de la persona, no se da la metamorfosis de individuo común a espectador. Pongamos por ejemplo el caso de una persona que sale de su trabajo para comer. A mitad de su camino nota que hay una pareja que tiene una ligera discusión. La persona los mira unos segundos tratando de entender el tema de la discusión. Sin embargo, al no encontrar un tema que le interese o signos de alarma que pudieran requerir su intervención sigue su camino. Un minuto después la pareja inicia un canto y un baile llamando la atención del resto de las personas para finalmente ejecutar un acto que incluso puede formar parte de una campaña publicitaria que invita a las personas a acudir a un teatro para presenciar toda la obra. Los (ahora sí) espectadores aplauden, reciben 
un folleto y comentan lo que acaban de presenciar. En cambio, la persona que pasó en el momento inadecuado sin entender lo que vio ni recibir un desenlace, nunca se enteró que presenció una obra, lo que lo inhabilita como espectador.

\section{Juzgar}

Una vez establecida la primera relación con la obra, el espectador inicia, consciente o inconscientemente, el juicio de la propuesta creativa que se le presenta. El juicio inicial se da en un nivel superficial y surge en paralelo con la primera exploración de la obra. El espectador no tiene tiempo de reflexionar en profundidad acerca de lo que se le ofrece. Las conclusiones originales nacen justo en el momento en que contempla someramente los detalles más obvios de la propuesta. Una vez concluida la revisión de la obra viene otro juicio más calmo y preciso que se soporta sobre la reflexión y la comparación con los parámetros acumulados en el bagaje del propio espectador. Este doble juicio se da para responder preguntas como:

- ¿Esta obra es de mi agrado?

- ¿Es del tipo de obras que suelo buscar?

- ¿Se dice algo de una manera novedosa?

- ¿Conozco el tema?

- ¿Conozco al autor?

- ¿La versión que se me presenta se apega a la estética y a la narrativa de la obra original?

- ¿Es una obra conocida interpretada de una nueva manera? Etcétera.

\section{Cuestionar $^{17}$}

En el cuestionamiento, el espectador debate consigo mismo la viabilidad y la calidad (de acuerdo con sus parámetros) de la obra. Las controversias resultantes retan al autor, a través de su propia reflexión. El espectador ya no se cuestiona si la obra pertenece a su género favorito. El espectador debate si la obra cumple con las promesas y calidad de estándares del género, si el producto creativo es creíble acorde a las reglas de su género y hasta qué punto. Discute muchos detalles del trabajo, de las relaciones que se dan entre los elementos, así como los elementos mismos, los resultados parciales o si la firmeza en el uso de los elementos narrativos usados por el creador son los adecuados, así como la suma final de la obra, todo en función de la construcción de una opinión sólida con base en sus saberes y entendimientos.

$17 \quad$ Es vital que quede entendido que esta función no se plantea como una posición ideológica como la presenta Rincón: "ser televidente es un acto individual, pero podemos devenir en comunidad, colectivo, solidaridad y confianza si somos capaces de juntarnos alrededor de temas, acciones, sujetos e ideales" (2008, p. 96). El cuestionamiento en este punto es acerca de la obra sin abordar conceptos de percepción de una realidad social. 
En esta fase surgen preguntas tales como:

- ¿LLa obra está a la altura de otras obras similares?

- ¿ंEs mejor?

- ¿Es peor?

- ¿Es viable?

- ¿ ¿Los elementos son coherentes, no solo con el género sino con la obra en sí?

- ¿Es creíble?

- ¿Se parece a otra similar?

\section{Creer o descreer}

Luego del tamiz de los cuestionamientos, el espectador llega a la confluencia donde decide si cree o descree de la propuesta del autor y, en consecuencia, de la obra misma. Por definición estas funciones son mutuamente excluyentes y el resultado afecta indefectiblemente a las funciones posteriores. Asimismo, es importante señalar que un descreimiento no necesariamente es sinónimo de un rechazo (ni tajante, ni parcial) de la obra. Esto se explica porque un espectador que se acerca a una obra de fantasía (literatura, cine, televisión u ópera) o surrealista (pintura o escultura, etcétera) no cree en la totalidad de lo que se le presenta, sino que cede su credibilidad a la historia solo cuando la estructura narrativa de la obra es coherente y apegada a lo que promete el autor ${ }^{18}$. Dos ejemplos de este tipo de obras, donde se entienden mejor las funciones de creer o descreer, son las películas de culto. Está el caso de los filmes de Juan Rogelio García García (Juan Orol), cineasta español que produjo sus películas en México. Un solo título de sus filmes puede ilustrar el punto: Gánsteres contra Charros de 1947. En Norteamérica aparece Edward Davis Wood, Jr. (Ed Wood) y un filme para ilustrar esto es: Bride of the Monster de 1955. En ambos casos, los argumentos no son creíbles por el absoluto alejamiento que tienen del género, los errores de continuidad y una dirección totalmente ajena a los cánones marcados como razonablemente buenos o aceptables. Sin importar qué se diga o cómo se diga ${ }^{19}$, el espectador tajantemente rechaza aceptar la credibilidad de dicha obra y, en algunos casos, asume de inmediato algunas funciones como criticar, halagar, denostar y rechazar. Esto echa por tierra los argumentos de algunos investigadores que afirman que una "buena" historia tiene que ser por definición verosímil:

18 Roldan lo refleja en su texto cuando habla de la relación espectador-actor: "El espectador, al tratarse de una identificación con el actor mediante la ilusión, vive lo que padece el actor pero sabiendo que no es real, es soportable" (2010, p. 4).

19 Al decir cómo se diga, incluso hablo de lo mucho o poco que el espectador capte durante la obra, dado que no es necesario que este entienda todos los signos incluidos en la obra. Basta que entienda lo global para ejercer esta función. Cómo dice Torrente: "Debido a la fragmentación que genera la cámara, el espectador debe de codificar por medio de un proceso cognitivo la información que el actor comunica y actúa; es decir, debe de entender en un sentido fractal, la parte por el todo y el todo por la parte (...). En lo audiovisual, el espectador debe de completar lo que la cámara deja de lado y también lo que decide mostrar. $(2015$, p, 23) 
Como se indica en extracto de diálogo, las emociones y el interés que una buena historia genera en lectores y espectadores (alerta, sorpresa, entretenimiento...) así como toda la habilidad en el decir, son sujetos de un solo principio: la búsqueda de la verosimilitud. (Sánchez-Escalonilla, 2013, p 81).

La verosimilitud no tiene, en este caso concreto, nada que ver con la credibilidad en el espectador. En el caso del creer o descreer, el espectador señala todos los defectos, pero puede halagar una obra que cruza las fronteras de lo malo para convertirse en pésima y la adopta como un producto del que se puede hacer mofa en casi cualquier sentido, por supuesto el extremo de esta función es la denostación. Asimismo, puede rechazar completamente la propuesta e incluso desacreditarla ante posibles nuevos espectadores, pero finalmente la reconoce como una propuesta creativa.

\section{Discriminar}

Ya sea que el espectador le crea o no a la obra, genera una dinámica en la que él suele elegir los elementos que a su juicio ameritan o demeritan más a la obra. La discriminación no solo aborda generalidades, sino que incluso puede señalar hasta los detalles más pequeños y específicos.

Se puede ilustrar esta mecánica imaginando a un espectador que juzga y cuestiona un filme o un libro sobre la base de que ciertos detalles (o la totalidad) son inadmisibles dada la falta de "veracidad narrativa". Sin embargo, esto no quiere decir que descalifique totalmente la obra. En el otro extremo encuentra las minucias (o generalidades) que, según su criterio, son lo mejor logrado de la obra. Tomemos por caso la novela Mundo anillo de Larry Niven publicada en 1970. Después de su primera edición los aficionados al género de la ciencia ficción le dieron una excelente acogida. Pero después de un tiempo:

Niven recibió numerosas cartas de admiración, pero también un número significativo de lectores (principalmente aficionados a la astronomía y a la física) planteaban en dichas cartas algunos de los "errores" que el autor había cometido al describir su mundo anular. En la Convención Mundial de Ciencia Ficción de 1970 había estudiantes de MIT en los pasillos que cantaban: "iEl Mundo Anillo es inestable! iEl Mundo Anillo es inestable!" (1987, Niven, p. 9)

\section{Criticar}

Una vez recorridas las primeras funciones, el espectador está en posición de emitir una crítica abierta de la obra, ante sí mismo o ante otros espectadores. Luego que ha discriminado y evaluado los elementos que componen la propuesta, emite su opinión a manera de crítica y "Así... [al] agregar elementos de análisis retóricos y pragmáticos... permite inferir y criticar para acceder al dominio en el que la actividad del espectador se convierte en necesaria para interpretar y reconstruir" (Alcolea, 2009, p. 260). Los resultados pueden ser variados, pues pueden ir, desde la mayoría de los elementos de la obra son malos y en consecuencia dicha propuesta es inaceptable, pasando por la posibilidad de que en la obra se sumen elementos buenos y malos por lo que puede ser calificada como regular, 
hasta que la estructura narrativa y estética de la propuesta convenza totalmente al espectador por todos los elementos positivos que incluye la obra y la califique como magnífica.

También puede darse el caso de que una obra adolezca de demasiados errores (voluntarios o involuntarios), sin embargo, los espectadores pueden juzgarla como excelente o al menos muy entretenida. Como ejemplo se puede citar la saga de los filmes Sharknado (2013); Sharknado 2: The Second One (2014) y Sharknado 3 Oh Hell No! (2015) todas dirigidas por Anthony C. Ferrante. Esta saga se basa en una anécdota totalmente inverosímil, con efectos visuales de poca calidad, también posee un guion repetitivo y las actuaciones son lamentables, en términos canónicos. Como otras obras similares, estas películas se convierten en filmes de culto y las personas suelen verlas con la intención de burla sí, pero evidentemente también para divertimento y, obviamente, los productores las siguen creando pues prueban ser redituables económicamente hablando.

\section{Halagar o vituperar}

Si el resultado de las funciones de discriminar y criticar es positivo, el espectador da el paso lógico y halaga la obra. Por el contrario, si para el espectador el resultado entregado por la obra es negativo, expresará duras críticas en forma de vituperaciones. Ambas expresiones se pueden dar para sí mismo o para terceros. No está por demás recordar que los criterios para ejercer esta función cambian de persona a persona, es decir lo que para una(s) persona(s) puede resultar una obra magnífica, para otras el resultado puede ser nefasto. Una situación donde se puede ver claramente esta opción para los espectadores son los géneros. Así, para un público femenino de edad entre adolescente y maduro joven, una película romántica puede parecer excepcionalmente bien lograda mientras que, para el público masculino, de las mismas características en edad, puede parecer absolutamente cursi y deleznable.

\section{Aceptar o rechazar}

Después de transitar todas las funciones, el espectador finalmente debe optar por cualquiera de estas funciones: aceptar ${ }^{20}$ o rechazar en definitiva la propuesta creativa que se le presenta. Estas dos últimas funciones son recíprocamente excluyentes. Este peldaño es la última de las funciones del espectador.

\section{¿Cómo evoluciona un espectador?}

Esta es una pregunta que podría parecer fácil de responder. Sin embargo, es necesario admitir que la complejidad del espectador, como objeto de estudio, hace imposible tomar vías rápidas o dar respuestas fáciles en cualquiera de las aristas que se pretenden explorar. En primera instancia ya he dicho que un espectador se hace con el hecho de contemplar

20 Cuando el espectador acepta una obra creativa se ubica en el contexto que Díaz define para los espectadores de documentales falsos: "los espectadores se muestran como cómplices del realizador cuando comparten las convenciones y códigos del falso documental o víctimas del mismo si son sorprendidos por sus intenciones" (2012, p. 155) 
una obra creativa y con la interacción que hace con ella, en consecuencia, todos, en un momento, nos convertimos en espectadores. Sin embargo, cuando el espectador se enfrenta por primera vez a la obra de un género determinado, simplemente la contempla, pues está en el proceso de aprendizaje para ser un espectador de ese tipo de obras en particular, pues los "mensajes no son recibidos uniformemente por todas las audiencias y el nivel de influencia que reciben varía en gran medida" (Happer y Philo, 2013, p. 326). De esta reflexión se deriva la afirmación de que no se puede comprender lo que no se conoce, pues generalmente lo desconocido pasa desapercibido. Es factible decir que, para iniciar la comprensión de un fenómeno, este no solo debe aparecer delante del espectador, sino que la persona debe darse cuenta de que existe, es entonces cuando empieza el proceso de desciframiento de cualquier objeto.

Luego de este primer encuentro, y en caso de que el espectador se aficione a las obras de un autor, de un género o de una disciplina, se crean relaciones más sólidas con un tipo de obras en particular ${ }^{21}$, cosa que difícilmente acontece cuando se está en las primeras etapas del proceso de consolidación como espectador. De este modo, la persona desarrolla cada día más sus capacidades para interactuar con los proyectos que los autores ${ }^{22}$ le presentan y asume el total de las funciones de los de su clase. La etapa superior donde el espectador es ya un conocedor, las describen perfectamente Jia, Shen, Epema e Iosup (2016). Cuando hablan de los expertos en los videojuegos: "juntos, jugadores y espectadores miran e incluso estudian los gamecast (el equivalente de grabaciones o producciones transmitidas en línea) de equipos o jugadores talentosos, algunas veces de manera repetida ya sea con propósitos de entretenimiento o educativos" (p. 2).

\section{¿Existe la conciencia del espectador cómo tal? Es decir, ¿el espectador es capaz de verse a sí mismo como espectador?}

El quid para responder puntualmente a esta pregunta está en el sentido en que usé anteriormente el término de espectador. Como dije, un espectador se da en función del enfrentamiento con una obra y su interacción con la misma. Por otro lado, también afirmé que el contexto de espectador debería ser más amplio y tendría que cubrir al lector de un libro, al jugador de videojuegos, al observador de un espectáculo callejero, al visitante a un museo, etcétera. De tal modo, si les preguntamos a algunos de ellos si se consideran espectadores lo más probable es que digan que no. Tal vez se den a sí mismos un adjetivo como jugador, lector o cualquier otro que encaje con una definición más bien ortodoxa.

${ }_{21}^{21}$ Me parece válido decir que ninguna obra es contemplada o comprendida en su totalidad por ningún espectador. Sin embargo, este último usa su capacidad para llenar los huecos con el fin de apreciar e interactuar con la obra, pues como afirma Prósper: "puede fallar ocasionalmente en un relato concreto algún procedimiento técnico pero el sistema sigue vigente. Y, lo mejor, el espectador no suele notarlo" (Prósper 2013, p. 383).

22 Si bien es cierto que el crecimiento del espectador a los niveles más altos se da por iniciativa propia, también es necesario reconocer que en muchos casos recibe incentivos de los autores alargando las obras, así los "productores construyen indicios estratégicos migratorios para dirigir a los aficionados a otros puntos de consumo dentro de la propia franquicia transmedia, con la intención de mantenerlos interesados en el rastreo de la conectividad o continuidad textual [de la obral" (Scott, 2017, p. 1047), donde entendemos a la transmedia como la migración de una narración de un medio a otro(s). 
Este problema semántico se extiende incluso en su propio concepto. Muchos lectores no se sienten lectores si no alcanzan cierto grado en la cantidad de libros que leen por año o en la calidad de los textos que abordan. En el caso de los jugadores de video juegos tal vez no se sientan jugadores si no han alcanzado la habilidad necesaria para vencer a cierto tipo de rivales o rebasado un determinado número de niveles de dificultad. Más bien se sienten "no jugadores", "no lectores", "no cinéfilos". Es decir, parece que la opinión general es que los conceptos de lector, jugador, cinéfilo y demás, solo puede o tiende a ser empleado en expertos. Sobre esta lógica es viable responder a la pregunta que nos hicimos. Los espectadores inexpertos no se saben ni se asumen como espectadores en su área favorita de contemplación. Es posible que algunos espectadores casuales sí se miren a sí mismos como espectadores en su campo. Por otro lado, los espectadores expertos, en definitiva, sí se asumen como espectadores. En otras palabras, la toma de conciencia de la propia condición de espectador se produce con el paso del tiempo, cuando la persona, a través de la experiencia, accede a la fase superior de la clasificación, es decir cuando se convierte en un experto en su área de goce. Además, existe otra variable que debemos tomar en cuenta con respecto al punto que nos ocupa: la conciencia colectiva de los espectadores.

La colectividad no solo se da cuando se mira en grupo un producto creativo, como el cine o el teatro, también se da cuando la contemplación puede parecer individual como en el caso de la literatura o de los cómics. Esta experiencia, que por sentido común parece individual, se torna colectiva cuando la persona que contempla la obra comparte sus experiencias con otros espectadores interesados en la misma obra, autor o género. A pesar de esta tendencia a la colectividad, en ninguna circunstancia es posible definir a los espectadores colectivos como una homogeneidad, dado que cada persona realiza la experiencia de la interactividad con la obra, de manera individual y personal.

Por otro lado, una característica de las personas aficionadas a enfrentarse a las obras creativas es que, una vez encaminadas en la ruta hacia el estatus de espectador experto, su contacto, análisis e interacción con las propuestas creativas se vuelve mucho más profundo y extenso. Por el contrario, el contacto con las obras del espectador inexperto y casual suele ser efímero y superficial. Estos espectadores no acostumbran a pasar más tiempo del necesario en la contemplación de la obra. No la cuestionan en profundidad, ni buscan segundas intenciones, ni efectos colaterales (anteriores o posteriores) alrededor de la propuesta que se les presenta, es decir su interacción se limita al momento del encuentro. En cambio, el público avezado, gracias a su afición al autor, obra o género se prepara mucho, antes de presenciar la obra. Esto lo arma con un considerable bagaje con que cuestionar a la propuesta. En consecuencia, su análisis es mucho más profundo pues su conocimiento también lo es.

\section{Papel del espectador}

El papel del que contempla una obra parece claro a primera vista pues se da en relación con los lazos entre el creador, la obra y el mismo espectador. La experiencia nos dice que: 
- El creador produce la obra, con base en su talento y a través de un detonador creativo, con sus limitaciones y aptitudes.

- La obra se convierte en el medio expresivo a través del cual el autor transmite su cosmovisión y propuesta creativa al espectador.

- El espectador acepta o rechaza la propuesta creativa.

Por supuesto, este esquema puede parecer por demás simple y superficial, a pesar de esto nos da pie a profundizar en él para hacerlo más sólido. Omitiremos las dos primeras etapas de esta dinámica pues no es la intención de este análisis abordarlas. En consecuencia, nos apegaremos a examinar la tercera fase que nos ayudó con anterioridad a comprender las funciones del espectador.

En primer lugar, debemos reflexionar si el punto tres, tal y como se escribió líneas arriba, basta para profundizar en el papel del espectador. En concordancia con la definición de espectador tendríamos que modificar dicho punto tres. Primero el espectador debe salir de su rutina para luego enfrentar a la obra y después rechazarla o aceptarla. ¿Pero, por qué se da la afirmación que debe enfrentarse? Definitivamente no puede existir una relación entre dos entidades que no se tocan en algún plano. Por ejemplo, no se puede ser espectador si no se ha visto un libro (al menos la portada) o se ha escuchado acera de él. El contacto obra-persona convierte a esta última en espectador, sin importar las consecuencias posteriores, sin importar el tipo de obra ni el tipo de autor. Resumiendo, el papel del espectador es completar la ecuación autor-obra-espectador.

\section{Conclusiones}

En conclusión, es factible decir que la literatura que aborde al espectador es comparativamente menor a la que se genera alrededor de la obra y del creador, incluso algunos textos que incluyen al espectador en su título terminan desviándose del tema. Sobre la base de esta carencia, en este artículo se propone una definición para trabajar con el concepto de espectador, a saber:

La persona que encuentra un rompimiento de la rutina a través del enfrentamiento con una obra creativa. Este encuentro puede ser accidental o provocado por el mismo espectador. De este contacto con la obra, es ineludible que la persona interactúe con esta expresión. Asimismo, derivados de dicha propuesta, la persona puede obtener estímulos lúdicos, estéticos o culturales.

En consecuencia, el espectador rompe su rutina al convertirse en espectador. Sin embargo, la obra que contemple debe ser, indefectiblemente, creativa. El enfrentamiento con la obra no necesariamente es voluntario. Si el espectador no interactúa con la obra no puede ser espectador pues sucede que él no sabe que está frente a una obra creativa. Una vez realizada la relación el espectador puede obtener estímulos lúdicos, estéticos o culturales de la obra. En esta propuesta, el concepto de obra se amplía y se redefine para abarcar los trabajos creativos artísticos, comerciales y todos aquellos que se encuentran en la zona gris entre ambos. Una vez desarrollada la reflexión acerca de los puntos 
anteriores planteamos las funciones que debe cumplir una persona para considerarse como espectador y que son: 1. Buscar, 2. Crear expectativas, 3. Contemplar, 4. Juzgar, 5. Cuestionar 6. Creer 7. Descreer, 8. Discriminar, 9. Criticar, 10. Halagar, 11. Vituperar, 12. Aceptar, 13. Rechazar.

Por otro lado, se hace referencia a la evolución de un espectador y se cuestiona si el espectador se sabe a sí mismo como espectador y se responde con la deliberación en el sentido que por sentido común el espectador solo se asume como tal cuando ha rebasado cierto nivel de conocimiento en relación con algún tipo de obras, género o autores. Finalmente se define el papel del espectador en donde el primer paso es entrar conscientemente en contacto con la obra para después asumir las funciones propias del espectador, todo para completar la ecuación autor-obra-espectador.

\section{Referencias}

Jia, A., Shen, S., Epema, D. y Iosup, A. (2016). When game becomes life: The creators and spectators of online game replays and live streaming. ACM Trans. Multimedia Comput. Commun. 12(4).

Alcolea, J. (2009). Visual Arguments in Film. Argumentation, 23(2), 259-275.

Andersen, K. (2005). Harry Potter and the Susceptible Child Audience. CLCWe6, 7(2), 2-10.

Aumont, J. (1992). La imagen. Madrid, España: Paidós.

Babatunde, B. y Simmons, R. (2007). A tale of two audiences: spectators, television viewers and outcome uncertainty in Spanish football. Journal of economics and business, 61(4), 326-338.

Cerezo Arriaza, M. (1996). La televisión: del espectador ingenuo al espectador crítico. Revista Comunicar, (6), 15-21.

Chabot, K. (2008). Audience, Sentimental Postmodernism, and Kiss of the Spider Woman. CLCWeb: Comparative Literature and Culture, 10(3).

Contreras, F. y Gasca, L. (2016). Las emociones del espectador en una experiencia fotográfica, pictórica y cinematográfica. Praxis y Saber, 7(14), 165 192.

De Souza Barros, M. (2015). Luzes sobre o Espectador: artistas e docentes em ação. Rev. Bras. Estud. Presença, 5(2), 330-355.

Díaz, V. (2012). Espectadores de falsos documentales. Los falsos documentales en la sociedad de la información. Athenea Digital, 12(3), 153-162.

Kirkkopelto, E. (2011). I am a Child. Hypothesis on Spectator Pedagogy. Ethics in Progress Quarterly (ethicsinprogress.org), 2(2), 81-87.

Happer, C. y Philo, G. (2013). The role of the media in the construction of public belief and social change. Journal of Social and Political Psychology, 1(1), 321-336.

Heddon, D., Iball, H., y Zerihan, R. (2012). Come closer: confessions of intimate spectators in one to one performance. Contemporary Theatre Review, 22 (1). 121-134.

Hernández, B. y Martín, J.L. (1998). La recepción de la obra de arte y la participación del espectador en las propuestas artísticas contemporáneas. Revista Española de Investigaciones Sociológicas, (84), 45-63. 
Lauwrens, J. (2012). Can you see what I mean? An exploration of the limits of vision in anti-ocularcentric contemporary art. De arte, (85), 26-41.

Liebers, N. y Schramm, H. (2017). Friends in books: The influence of character attributes and the reading experience on parasocial relationships and romances. Poetics, 65, 12-23.

Loscertales, F. y Núñez, T. (2008). Ver cine en TV: una ventana a la socialización familiar. Comunicar, $\mathrm{XVI}(31), 137-143$.

Lopes, F. y Loureiro, L. (2011). My Newscast Is No Longer Ours. Journalism and Mass Communication, 1(3), 201-212.

Massara, G., Sabeckis, C. y Vallazza, E. (2018). Tendencias en el cine expandido contemporáneo. Cuadernos del centro de estudios en diseño y comunicación. Ensayos, (66), 157-172.

Moreno, M. (2006). Educar espectadores: propuestas expositivas y dinamización. Comunicar, (28), $211-228$.

Niven, Larry. (1987). Los ingenieros del mundo anillo. Ciudad de México: Ediciones Roca, S.A.

O'Neill, B. (2006). Experiences of interaction and participation in media communication in a digital environment. IAMCR Annual Congress, El Cairo, Egipto

O’Neill, B., Gallego, J. I. y Zeller, F. (2013). New perspectives on audience activity: 'prosumption' and media activism as audience practices. En N. Carpentier, K. Schrøder. y L. Hallett (eds.), Audience Transformations: Shifting Audience Positions in Late Modernity (pp.157 171). Londres: Routledge.

Ortega y Gasset, J. (1985). El espectador. Madrid: Alianza Editorial

Pimentel, L. A. (2010). El relato en perspectiva. Estudio de teoría narrativa. Ciudad de México: Siglo XXI Editores.

Prósper, J. (2013). El sistema de continuidad: montaje y causalidad. Historia y Comunicación Social, 18(1), 377-386.

Rincón, O. (2008). No más audiencias, todos devenimos en productores. Comunicar, 15(30), 93-98.

Roldán, C. (2010). El actor y el espectador. De freud a Lacan. Revista Affectio Societatis, 7(13).

Sánchez-Escalonilla, A. (2013). Verisimilitude and Film Story: the links between Screenwriter, Character and Spectator. Comunication E Society, 26(2), 79-94.

Scott, S. (2017). Modeling the Marvel everyfan: Agent Coulson and/as transmedia fanculture. Palabra Clave, 20(4), 1042-1072. DOI: 10.5294/pacla.2017.20.4.8.

Torrente, P. (2015). La sutura de lo ausente. El espectador como actor en el videoarte. Cuaderno, 52,19-29. 